\title{
Estimation of thermal neutron flux in pet cyclotron rooms by means of radioactive analysis of bolts in the rooms
}

\author{
By Y. Ogata',*, N. Ishigure ${ }^{1}$, S. Mochizuki ${ }^{1}$, K. Ito ${ }^{2}$, K. Hatano ${ }^{2}$, J. Abe ${ }^{2}$, H. Miyahara ${ }^{3}$, K. Masumoto ${ }^{4}$ H. Nakamura ${ }^{4}$, \\ Y. Ito ${ }^{5}$, E. Yamashita ${ }^{6}$ and T. Kobayashi ${ }^{6}$ \\ ${ }^{1}$ School of Health Sciences, Nagoya University, Daiko-minami, Higashi-ku, Nagoya, 461-8673, Japan \\ 2 National Institute for Longevity Sciences, Morioka-machi, Obu, Aichi Prefecture, 474-8511, Japan \\ ${ }^{3}$ Gifu University of Medical Science, Nagamine, Ichihiraga, Seki, Gifu Prefecture, 501-3892, Japan \\ ${ }_{5}^{4}$ High Energy Accelerator Research Organization, Oho, Tsukuba, Ibaragi Prefecture, 305-0801, Japan \\ 5 Nagoya Rehabilitation Center, Yadomi-cho, Mizuho-ku, Nagoya, 467-8622, Japan \\ ${ }^{6}$ Nagoya Diagnostic Radiology Foundation, Jiyu-gaoka, Chikusa-ku, Nagoya, 464-0044, Japan
}

(Received December 1, 2009; accepted December 20, 2010)

\section{Thermal neutron fluxes / PET cyclotron / Bolts / Gamma spectrometry}

\begin{abstract}
Summary. Short-lived radionuclides for positron emission tomography (PET) examinations in medicine are produced mainly using on site small cyclotrons. The operation of the cyclotron generates a significant quantity of neutrons, which will activate the cyclotron and surrounding materials. A new technique is proposed to estimate the neutron fluxes in the cyclotron rooms, in which small bolts in the cyclotron rooms were used as surrogates for neutron detectors. The measurements were carried out at four PET cyclotrons. The induced radioactivity of the bolts was analyzed by gamma-ray spectroscopy and elemental analysis. A gold foil activation method was applied to compare the results. The neutron fluxes in the PET cyclotron rooms were in the range of $10^{5} \sim 10^{6} \mathrm{~cm}^{-2} \mathrm{~s}^{-1}$ during ${ }^{18} \mathrm{~F}$ production. In the brass bolts, ${ }^{69 \mathrm{~m}} \mathrm{Zn},{ }^{65} \mathrm{Zn},{ }^{64} \mathrm{Cu}$, ${ }^{58} \mathrm{Co}$, and ${ }^{60} \mathrm{Co}$ were detected. In the iron bolts, ${ }^{56} \mathrm{Mn},{ }^{54} \mathrm{Mn}$, ${ }^{59} \mathrm{Fe},{ }^{60} \mathrm{Co},{ }^{69 \mathrm{~m}} \mathrm{Zn}$, and ${ }^{65} \mathrm{Zn}$ were detected. In the stainless steel bolts, ${ }^{58} \mathrm{Co},{ }^{60} \mathrm{Co},{ }^{56} \mathrm{Mn},{ }^{54} \mathrm{Mn}$, and ${ }^{59} \mathrm{Fe}$ were detected. Neutron fluxes estimated from the activities of ${ }^{56} \mathrm{Mn}$ agreed well with those by the $\mathrm{Au}$ foil method. The feasibility of estimating the neutron fluxes in cyclotron rooms by means of radioactive analysis of bolts in the rooms was proven.
\end{abstract}

\section{Introduction}

Positron Emission Tomography (PET) examinations are used world-wide for exploring brain function, the position of cancers, etc., as a non-invasive exploration method [1-3]. According to the Committee on PET Nuclear Medicine, the Japanese Society of Nuclear Medicine, the number of the PET cyclotrons totals 135 in July 2009 in Japan, and the number is still increasing (PET\&PET 2009) [4]. As positron emission nuclides for the PET examination have quite short half-lives, they are mainly produced by on-site cyclotrons. Significant quantities of radiations are generated with the operation of the cyclotrons, i.e., gamma rays,

\footnotetext{
*Author for correspondence (E-mail: ogata@met.nagoya-uac.jp).
}

bremsstrahlung photons, beta rays, and neutrons. Among them, the neutrons have the potential to activate the materials in the room, such as the cyclotron body; components around the cyclotron such as the target foils, target box, and shieldings, equipment in the room; as well as the walls, the ceiling and the floor of the room.

There are some reports for those radioactive by-products resulting from the operation of PET cyclotrons [5-9]. Those activated materials will ultimately become a certain amount of radioactive waste in maintaining or decommissioning the cyclotron. It is effective for assessing the amount of those activated materials to estimate the neutron fluxes and their distribution. The estimations will bring valuable information for appropriate shielding methods to reduce such a radioactive waste. Furthermore, the quantification of the effective dose of neutron in areas occupied by the medical staff provides effective safety information for the staff.

There are several reports about estimating the neutron flux around PET cyclotrons [10-15]. Obviously, the neutron flux is dependent on the acceleration voltage, the kind of the charged particle and the current, and the structure of the cyclotron and the room, etc., so it is not easy to generalize. However, assembling data from the neutron fluxes at those cyclotrons, including the data in this work, will provide effective knowledge to help with the design of PET cyclotrons and the rooms. The data assembly will contribute to improve radiation protection and to provide valuable estimates of the amount of radioactivity which can be induced. However, to measure the neutron flux is not so easy because it needs special instruments and techniques. There are insufficient instruments and techniques to measure neutrons in most hospitals. Without reliable estimation of the neutron intensity, most medical staff would rely only upon the reports estimated by the manufacturers of the cyclotron.

To evaluate the neutron fluxes is one of the measures to achieve radiation safety on the maintenance of the cyclotrons, to assess the amount of the radioactive wastes, and to estimate the exposures. A new technique is proposed to estimate the neutron fluxes in the cyclotron rooms, in which small bolts or screws in the cyclotron rooms are used as sur- 
Table 1. Characteristics of the cyclotrons.

\begin{tabular}{|c|c|c|c|c|}
\hline Facility & $\begin{array}{l}\text { (A) } \\
\text { National Institute for } \\
\text { Longevity Sciences }\end{array}$ & $\begin{array}{c}\text { (B) } \\
\text { Nagoya Rehabilitation } \\
\text { Center }\end{array}$ & $\begin{array}{c}(\mathrm{C}) \\
\text { Nagoya PET } \\
\text { Imaging Center }\end{array}$ & $\begin{array}{c}\text { (D) } \\
\text { East Nagoya Imaging } \\
\text { Diagnosis Center }\end{array}$ \\
\hline Model & $\begin{array}{c}\text { Cypris HM-18 } \\
\text { Sumitomo Heavy } \\
\text { Industries }\end{array}$ & $\begin{array}{c}\text { Cypris } 370 \\
\text { Sumitomo Heavy } \\
\text { Industries }\end{array}$ & $\begin{array}{c}\text { Cyclone 18/9 } \\
\text { IBA/JFE }\end{array}$ & $\begin{array}{c}\text { Cyclone 10/5 } \\
\text { IBA/JFE }\end{array}$ \\
\hline $\begin{array}{l}\text { Acceleration } \\
\text { voltage }\end{array}$ & $\begin{array}{l}18 \mathrm{MV}(\mathrm{H}-) \\
10 \mathrm{MV}(\mathrm{D}-)\end{array}$ & $\begin{array}{l}18 \mathrm{MV}(\mathrm{H}+) \\
10 \mathrm{MV}(\mathrm{D}+)\end{array}$ & $\begin{array}{l}18 \mathrm{MV}(\mathrm{H}-) \\
10 \mathrm{MV}(\mathrm{D}-)\end{array}$ & $\begin{array}{l}10 \mathrm{MV}(\mathrm{H}-) \\
5 \mathrm{MV}(\mathrm{D}-)\end{array}$ \\
\hline $\begin{array}{l}\text { Mean charged } \\
\text { particle current }\end{array}$ & $20 \mu \mathrm{A}$ & $20 \mu \mathrm{A}$ & $30 \mu \mathrm{A}$ & $30 \mu \mathrm{A}$ \\
\hline Established & Nov 1995 & Jan 1990 & Oct 2007 & Oct 2001 \\
\hline Main products & $\begin{array}{l}{ }^{18} \mathrm{~F}:{ }^{18} \mathrm{O}(p, n) \\
{ }^{11} \mathrm{C}:{ }^{14} \mathrm{~N}(d, \alpha) \\
{ }^{15} \mathrm{O}:{ }^{14} \mathrm{~N}(d, n)\end{array}$ & $\begin{array}{l}{ }^{18} \mathrm{~F}:{ }^{18} \mathrm{O}(p, n) \\
{ }^{18} \mathrm{~F}:{ }^{20} \mathrm{Ne}(d, \alpha) \\
{ }^{11} \mathrm{C}:{ }^{14} \mathrm{~N}(d, \alpha) \\
{ }^{15} \mathrm{O}:{ }^{14} \mathrm{~N}(d, n)\end{array}$ & ${ }^{18} \mathrm{~F}:{ }^{18} \mathrm{O}(p, n)$ & ${ }^{18} \mathrm{~F}:{ }^{18} \mathrm{O}(p, n)$ \\
\hline
\end{tabular}

rogates for neutron detectors. The purpose of this study is to assess the feasibility of estimating the neutron fluxes in cyclotron rooms by means of radioactive analysis of the bolts in the rooms.

\section{Materials and methods}

The experiments were performed on four PET cyclotrons at medical facilities around the Nagoya region in Japan. The cyclotrons are used for producing radionuclides with short half-lives for PET examinations, i.e. ${ }^{18} \mathrm{~F},{ }^{11} \mathrm{C}$, and ${ }^{15} \mathrm{O}$. The characteristics of the cyclotrons are listed in Table 1. The acceleration voltage for proton for three of them was $18 \mathrm{MV}$ and that for one of them was $10 \mathrm{MV}$. A photograph of one of them; Cypris 18/10 in Nagoya PET Imaging Center (facility A) is shown in Fig. 1. The plane views around the PET cyclotron rooms are illustrated in Fig. 2. All of the cyclotrons were housed in a room with 1.5-1.8 $\mathrm{m}$ thickness of concrete walls for shielding against the radiations.

Several bolts or screws on wall sockets or on accessories in the rooms were removed to analyze both the activities and the elementary compositions. Fig. 3 shows samples of the bolts and Au foils on an accessory in the cyclotron room at the facility A. The activities were measured with a well type high purity Ge (HPGe) detector (GWL-300-15-S, Ortec). The compositions were analyzed using a fluorescent X-ray spectroscopy (ZSX100e, Rigaku), an electron probe micro analyzer (EPMA, JXA-8900RL WD/ED, JEOL), and an inductively coupled plasma atomic emission spectrometer (ICP-AES, OPTIMA 3300 RL, Perkin Elmer).

The method to calculate the neutron fluxes by the radioactive analysis of the bolts is mentioned below. The residual activity of a radionuclide in a bolt induced by $i$-th operation of a cyclotron, $A_{i}(\mathrm{~Bq})$, is expressed in an Eq. (1).

$$
A_{i}=\phi K N \sigma\left(1-e^{-\lambda t_{i}}\right) e^{-\lambda T w_{i}},
$$

where $\phi\left(\mathrm{cm}^{-2} \mathrm{~s}^{-1}\right)$ is the neutron flux at the bolt, $K$ is the abundance ratio of the target nuclide, $N$ is the number of the atoms of the target element in the bolts, $\sigma\left(\mathrm{cm}^{2}\right)$ is the

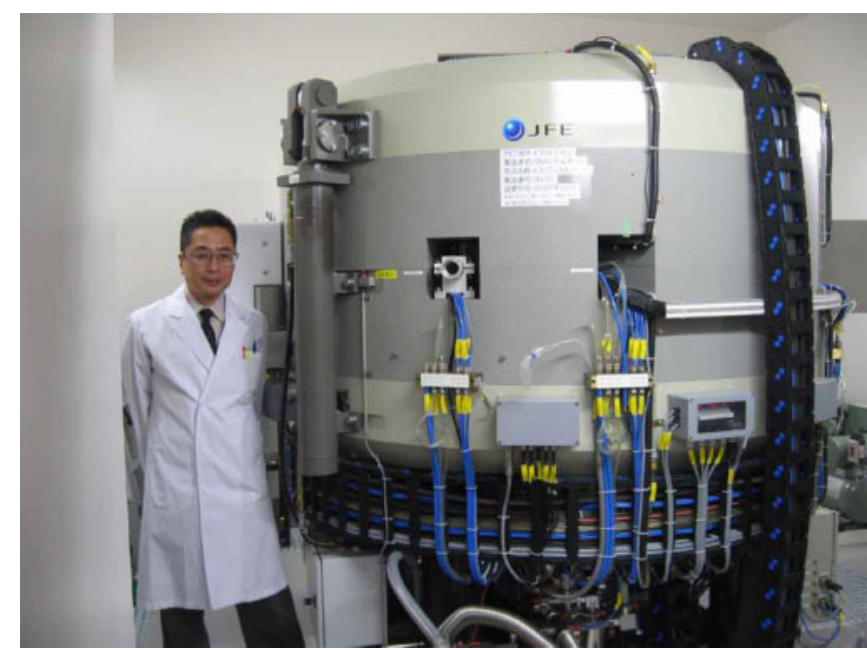

Fig. 1. One of the cyclotrons; Cypris 18/10 in the Nagoya PET Imaging Center.

neutron cross section, $\lambda\left(\mathrm{s}^{-1}\right)$ is the decay constant of the induced nuclide, $t_{i}(\mathrm{~s})$ is the time of the $i$-th operation, and $T w_{i}$ (s) is the time from the end of the $i$-th operation to the measurement of the activity. As the total activity of the induced nuclide in the bolt, $A(\mathrm{~Bq})$, is $\sum A_{i}$, the neutron flux, $\phi$, is,

$$
\phi=\frac{A}{K N \sigma \sum_{i}\left(1-e^{-\lambda t_{i}}\right) e^{-\lambda T w_{i}}} .
$$

To evaluate the thermal neutron fluxes in the cyclotron rooms, the gold foil activation method was carried out. Several pairs of $\mathrm{Au}$ foils were used for the method, each piece of the foil being $10 \mathrm{~mm} \times 10 \mathrm{~mm}$ and $0.1-\mathrm{mm}$ thick. One of the pair was covered with 1-mm thickness of $\mathrm{Cd}$ plates to absorb thermal neutrons and hence detected the epithermal neutrons. The Au foils were placed near to the bolts during the operation of the cyclotron. After the operation the $\mathrm{Au}$ foils with relatively high activities were measured with a closed-ended coaxial type high-purity germanium detector (GEM-35190-S, Ortec), and the others were measured 


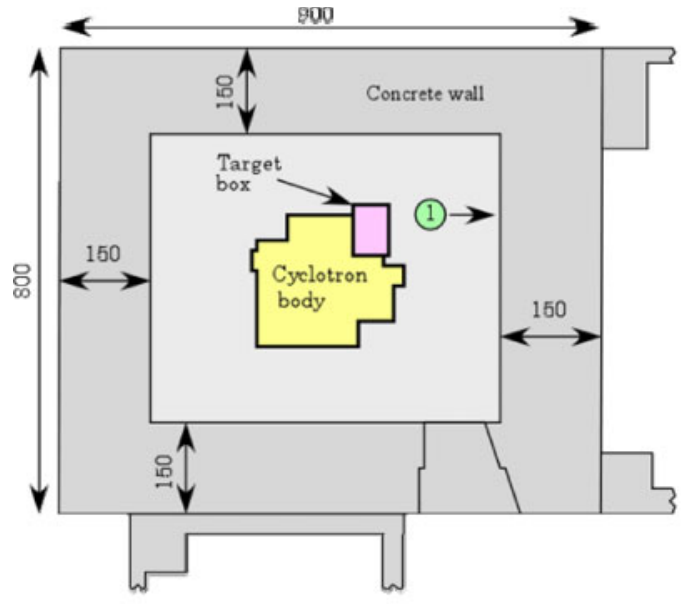

(A)

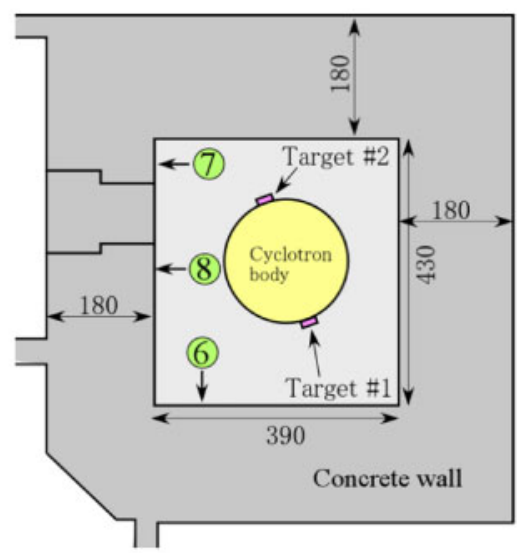

(C)

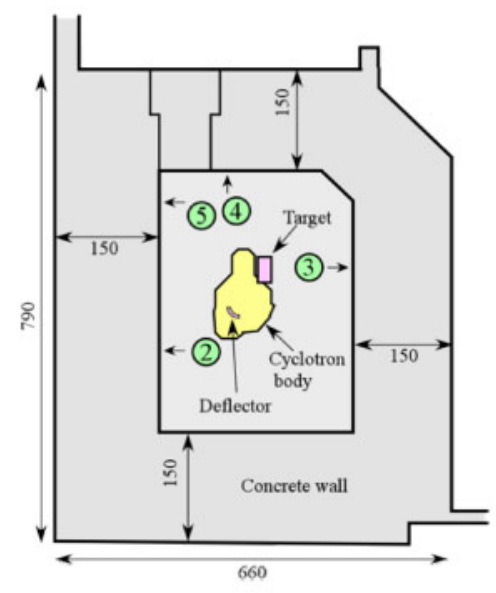

(B)

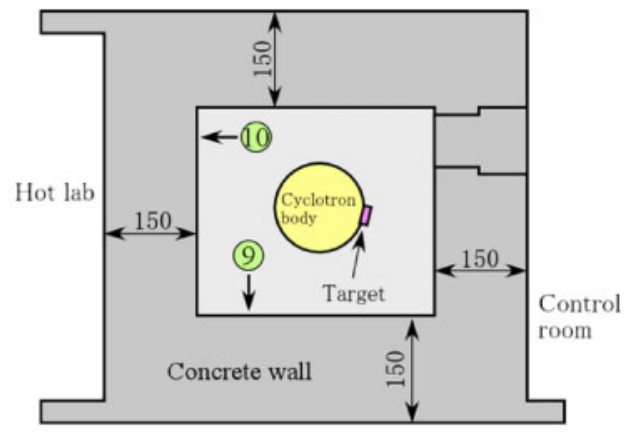

(D)

Fig. 2. Plane view of the cyclotron rooms and the positions of the bolts and Au foils. The encircled numbers indicate the position of the bolts and the $\mathrm{Au}$ foils. The dimensions are in $\mathrm{cm}$.

with the well type HPGe detector. The induced activities of ${ }^{198} \mathrm{Au}$ in the foils were analyzed from the gamma ray spectra. The thermal neutron flux, $\phi_{\mathrm{th}}$, were computed using Eq. (3) [16].

$$
\phi_{\mathrm{th}}=\frac{R_{\mathrm{th}}}{N \sigma}=\frac{R_{\mathrm{bare}}\left(1-\frac{F_{\mathrm{cd}}}{(P R)_{\mathrm{cd}}}\right)}{N \sigma f\left(1-F_{\mathrm{cd}}(T R)_{\mathrm{cd}}\right)},
$$

where $R_{\mathrm{th}}$ is the reaction rate of thermal neutron, $R_{\mathrm{bare}}$ is the total reaction rate of the $\mathrm{Au}$ foil without $\mathrm{Cd}, N$ is the number of $\mathrm{Au}$ atoms in the $\mathrm{Au}$ foil without $\mathrm{Cd}, \sigma$ is the thermal neutron cross section ( $98.8 \mathrm{barn}), F_{\mathrm{cd}}$ is the correction factor of thermal neutron, $(P R)_{\mathrm{cd}}$ is the Cd ratio, $f$ is the perturbation factor, and $(T R)_{\text {cd }}$ is the thermal neutron translation rate of the $\mathrm{Cd}$ cover.

The experimental conditions are listed in Table 2, and the positions of the bolts and the Au foils are indicated in Fig. 2. The cyclotrons were routinely operated for 30-60 $\mathrm{min}$ in early morning to produce the radiopharmaceuticals for PET examination. The $\mathrm{Au}$ foils were put on in the room at the evening of the previous day of the operation. Several hours after the end of the operation while waiting for the decrease of the radiations in the room, the Au foils were collected and
Table 2. Experimental conditions.

\begin{tabular}{|c|c|c|c|c|}
\hline Facility & (A) & (B) & (C) & (D) \\
\hline $\begin{array}{l}\text { Acceleration } \\
\text { and current }\end{array}$ & $\begin{array}{c}18 \mathrm{MV}(\mathrm{H}-) \\
20 \mu \mathrm{A}\end{array}$ & $\begin{array}{c}18 \mathrm{MV}(\mathrm{H}+) \\
20 \mu \mathrm{A}\end{array}$ & $\begin{array}{c}18 \mathrm{MV}(\mathrm{H}-) \\
30 \mu \mathrm{A}\end{array}$ & $\begin{array}{c}10 \mathrm{MV}(\mathrm{H}-) \\
30 \mu \mathrm{A}\end{array}$ \\
\hline Reaction & ${ }^{18} \mathrm{O}(p, n){ }^{18} \mathrm{~F}$ & ${ }^{18} \mathrm{O}(p, n){ }^{18} \mathrm{~F}$ & ${ }^{18} \mathrm{O}(p, n){ }^{18} \mathrm{~F}$ & ${ }^{18} \mathrm{O}(p, n){ }^{18} \mathrm{~F}$ \\
\hline $\begin{array}{l}\text { Operation } \\
\text { time }\end{array}$ & $90 \mathrm{~min}$ & $90 \mathrm{~min}$ & $36 \mathrm{~min}$ & $40 \mathrm{~min}$ \\
\hline Yield & $34.5 \mathrm{GBq}$ & $55 \mathrm{GBq}$ & $43 \mathrm{GBq}$ & $19 \mathrm{GBq}$ \\
\hline
\end{tabular}

the bolts in the room were removed. The activities of the $\mathrm{Au}$ foils and the bolts were measured for $200 \sim 50000 \mathrm{~s}$ with the HP Ge detectors.

\section{Results and discussion}

The elementary compositions of the bolts are shown in Table 3. Some bolts were made of nickel plated brass and others were made of iron or stainless steel. The brass bolts included $\mathrm{Zn}$ and $\mathrm{Cu}$, the iron bolts included $\mathrm{Fe}, \mathrm{Mn}$, and $\mathrm{Zn}$, 
Table 3. Elemental compositions of the bolts.

\begin{tabular}{|c|c|c|c|c|c|c|c|}
\hline Exp. & (A) & (B) & (C) & (C) & (D) & (D) & (D) \\
\hline Bolt\# & $\# 1$ & \#2 \#4 & $\# 6, \# 7$ & $\# 8$ & \#9 & $\# 10$ & $\begin{array}{c}\# 10 \\
\text { (magnetic) }\end{array}$ \\
\hline Material & $\begin{array}{l}\text { Ni plated } \\
\text { brass }\end{array}$ & $\begin{array}{l}\text { Ni plated } \\
\text { brass }\end{array}$ & $\begin{array}{l}\text { Zn plated } \\
\text { Fe }\end{array}$ & $\mathrm{Fe}$ & $\begin{array}{l}\text { Ni plated } \\
\text { brass }\end{array}$ & $\begin{array}{l}\text { Stainless } \\
\text { steel }\end{array}$ & $\begin{array}{l}\text { Stainless } \\
\text { steel }\end{array}$ \\
\hline \multirow[t]{2}{*}{ Meas. } & $\begin{array}{c}\text { Fluorescent } \\
\text { X-ray }\end{array}$ & EPMA $^{a}$ & $\begin{array}{l}\text { EPMA, } \\
\text { ICP-AES }^{b}\end{array}$ & EPMA & EPMA & EPMA & EPMA \\
\hline & \multicolumn{7}{|c|}{ Elemental composition (w/w\%) } \\
\hline $\mathrm{Cu}$ & 65 & 65 & - & - & 65 & 3.5 & - \\
\hline $\mathrm{Zn}$ & 34 & 34 & 1.72 & - & 34 & - & - \\
\hline $\mathrm{Fe}$ & - & - & 98 & 99 & - & 66 & 71 \\
\hline $\mathrm{Mn}$ & - & - & 0.98 & 1 & - & 1.3 & 1 \\
\hline $\mathrm{Cr}$ & - & - & - & - & - & 18 & 19 \\
\hline $\mathrm{Ni}$ & - & - & - & - & - & 9.5 & 8 \\
\hline $\mathrm{Si}$ & - & - & - & - & - & 0.2 & 0.5 \\
\hline Co & - & - & - & - & - & 0.5 & 0.4 \\
\hline V & - & - & - & - & - & - & 0.3 \\
\hline
\end{tabular}

a: EPMA; Electron Probe Micro Analyzer;

b: ICP-AES; Inductively Coupled Plasma Atomic Emission Spectrometer.

and the stainless steel bolts included $\mathrm{Fe}, \mathrm{Cr}, \mathrm{Ni}, \mathrm{Cu}, \mathrm{Si}, \mathrm{Co}$, and $\mathrm{V}$.

The neutron fluxes in the cyclotron rooms during ${ }^{18} \mathrm{~F}$ production were evaluated $2 \sim 9 \times 10^{5} \mathrm{~cm}^{-2} \mathrm{~s}^{-1}$ and the $\mathrm{Cd}$ ratios were within the range of $1.5 \sim 3.2$ by means of the $\mathrm{Au}$ activation method. The Cd ratio suggested that the neutrons in the rooms were relatively thermalized, but there existed certain amount of epithermal and fast neutrons.

All of the bolts were measured twice; the first time measured as soon as possible to detect short half-life nuclides, and then measured again after several days to detect longer half-life nuclides. Fig. 4 indicates gamma-ray spectra of an iron bolt in facility C, Fig. 4a was the one measured $6.7 \mathrm{~h}$ after the last operation, and Fig. $4 \mathrm{~b}$ was the other measured $2.16 \mathrm{~d}$ after. As a result of the gamma spectroscopy, the major radionuclides in the bolts are listed in Table 4 . In the brass bolts, ${ }^{69 \mathrm{~m}} \mathrm{Zn},{ }^{65} \mathrm{Zn},{ }^{64} \mathrm{Cu},{ }^{58} \mathrm{Co}$, and ${ }^{60} \mathrm{Co}$ were detected. In the iron bolts, ${ }^{56} \mathrm{Mn},{ }^{54} \mathrm{Mn},{ }^{59} \mathrm{Fe},{ }^{60} \mathrm{Co},{ }^{69 \mathrm{~m}} \mathrm{Zn}$, and ${ }^{65} \mathrm{Zn}$ were detected. In the stainless bolts, ${ }^{58} \mathrm{Co},{ }^{60} \mathrm{Co},{ }^{56} \mathrm{Mn},{ }^{54} \mathrm{Mn}$, and ${ }^{59} \mathrm{Fe}$ were detected. Table 5 lists the thermal neutron fluxes estimated from the $\mathrm{Au}$ activation method and those from radioactive analysis of brass bolts and Table 6 lists those from the Au method and those from radioactive analysis of iron and stainless bolts. The reason why the neutron fluxes were averaged at the bolt \#6' and \#7' in the facility $\mathrm{C}$ is as follows; the cyclotron has two target positions and the position was changed day by day. When the experiment was carried out, the target near to bolt \#6 was used. The other target was near to bolt \#7. Then when estimating the neutron fluxes from the activities of nuclides with longer half-lives, i.e. ${ }^{59} \mathrm{Fe}$ and ${ }^{65} \mathrm{Zn}$, the comparable neutron fluxes evaluated from the Au foil method were averaged using the values from both places.

In facility A in Table 5, the neutron fluxes were relatively different from each other since the $\mathrm{Au}$ foils were placed somewhat apart from the bolts. In facility $\mathrm{C}$ and $\mathrm{D}$, the neutron fluxes estimated from the activity of ${ }^{56} \mathrm{Mn}$ in the iron

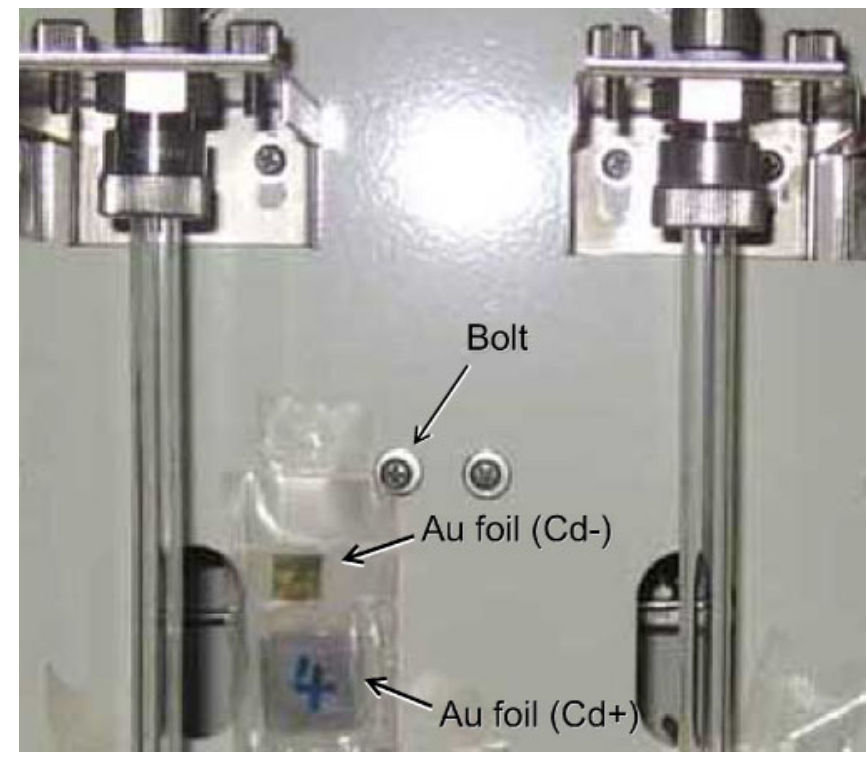

Fig. 3. A sample of the bolt to be meaured and a pair of gold foils. This is an assembly in the cyclotron room at the East Nagoya Imaging Diagnosis Center.

bolts agreed with those evaluated by the Au foil activation method within $25 \%$ differences. Since the half-life of ${ }^{56} \mathrm{Mn}$ is short at $2.6 \mathrm{~h}$, the remaining activity in a bolt reflects only the last operation. The Au foils were irradiated at an operation that was actually the last operation. Therefore, the neutron fluxes estimated from the activities of ${ }^{56} \mathrm{Mn}$ agreed with those evaluated by the Au foil method. On the other hand, the neutron fluxes estimated from the other nuclides were $1.2 \sim 2.4$ times higher than those evaluated from the $\mathrm{Au}$ foil method. Those radionuclides reflected the operations from the past several days to several years depending on the half-lives. That should be one of the reasons for the differences of the neutron fluxes between the radioactive analysis of the bolts and the Au foil method. Another reason for the 

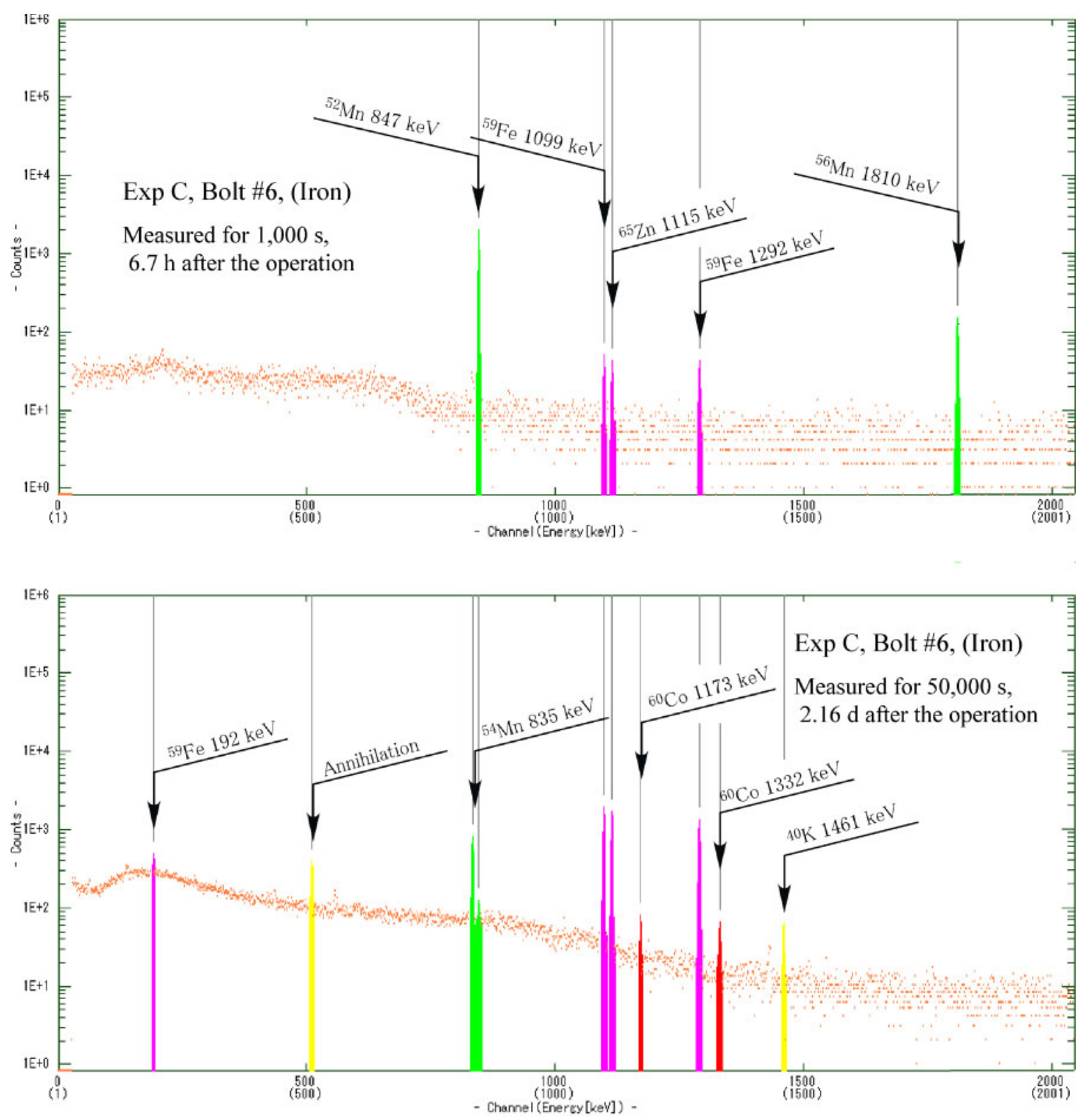

Fig. 4. Spectra of the iron bolt \#6 in the Nagoya PET Center. The upper one, (a), was measured $6.7 \mathrm{~h}$ after the operation, and (b) was $2.16 \mathrm{~d}$ after.

Table 4. Induced radionuclides and their activities in $\mathrm{Bq}$ at the end of operation.

\begin{tabular}{lccccc}
\hline Exp. & $(\mathrm{A})$ & $(\mathrm{B})$ & $(\mathrm{C})$ & $(\mathrm{D})$ & (D) \\
\hline Bolt & $\# 1$ & $\# 4$ & $\# 6$ & $\# 9$ & $\# 10$ \\
Material & Brass & Brass & Iron & Brass & Stainless steel \\
Weight $(\mathrm{g})$ & 1.2571 & 0.6390 & 1.805 & 1.2934 & 3.2689 \\
${ }^{69 \mathrm{~m}} \mathrm{Zn}$ & $0.58 \pm 0.06$ & $10.6 \pm 0.5$ & $0.13 \pm 0.02$ & $0.69 \pm 0.03$ & - \\
${ }^{65} \mathrm{Zn}$ & $23.7 \pm 0.3$ & $51.9 \pm 0.2$ & $2.27 \pm 0.03$ & $19.2 \pm 0.1$ & - \\
${ }^{64} \mathrm{Cu}$ & $216 \pm 14$ & $4270 \pm 140$ & - & $268 \pm 6$ & - \\
${ }^{58} \mathrm{Co}$ & $0.04 \pm 0.01$ & $0.59 \pm 0.03$ & - & - & $0.15 \pm 0.02$ \\
${ }^{60} \mathrm{Co}$ & $0.029 \pm 0.005$ & $0.45 \pm 0.02$ & $0.033 \pm 0.005$ & - & $12.5 \pm 0.1$ \\
${ }^{56} \mathrm{Mn}$ & - & - & $119 \pm 3$ & - & $93 \pm 3$ \\
${ }^{54} \mathrm{Mn}$ & - & - & $0.08 \pm 0.01$ & - & $0.15 \pm 0.02$ \\
${ }^{59} \mathrm{Fe}$ & - & - & $1.88 \pm 0.03$ & - & $0.58 \pm 0.04$ \\
\hline
\end{tabular}

differences may be that there were significant quantities of neutrons with relatively high energy in the rooms. One of the further assignments is to reduce the differences through the analysis of the neutron spectra.
According to some articles reported neutron spectra in the cyclotron vault room, there are significant quantity of fast neutrons [10-14]. The whole energy of neutrons will contribute the activation of the bolts. Although the Au foil 
Table 5. Thermal neutron flux estimated from the $\mathrm{Au}$ activation method and from the activities of the brass bolts. The neutron fluxes are in $10^{5} \mathrm{~cm}^{-2} \mathrm{~s}^{-1}$.

\begin{tabular}{lcccccccc}
\hline \multirow{2}{*}{$\begin{array}{c}\text { Exp. } \\
\end{array}$} & $\begin{array}{c}\text { Bolt } \\
\end{array}$ & & $\begin{array}{c}\text { Au } \\
\text { method }\end{array}$ & \multicolumn{2}{c}{${ }^{64} \mathrm{Cu}$} & \multicolumn{2}{c}{${ }^{69 \mathrm{~m}} \mathrm{Zn}$} & \multicolumn{2}{c}{${ }^{65} \mathrm{Zn}$} \\
\cline { 3 - 8 } & & $\phi_{\text {th }}$ & $\phi_{\text {th }}$ & Ratio $^{a}$ & $\phi_{\text {th }}$ & Ratio $^{a}$ & $\phi_{\text {th }}$ & Ratio $^{a}$ \\
\hline (A) & $\# 1$ & 9.1 & 6.3 & 69 & & - & 4.6 & 51 \\
\hline (B) & $\# 2$ & 5.1 & 8.4 & 164 & 8.0 & 157 & 7.7 & 151 \\
& $\# 3$ & 7.0 & 12 & 168 & 13 & 186 & 9.8 & 140 \\
& $\# 4$ & 9.8 & 18 & 129 & 20 & 200 & 14 & 145 \\
& $\# 5$ & 8.1 & 13 & 144 & 15 & 188 & 11 & 140 \\
\hline (D) & $\# 9$ & 1.5 & 2.3 & 157 & 2.7 & 186 & 3.5 & 242 \\
\hline
\end{tabular}

a: Value when the neutron flux from the Au method equals 100.

Table 6. Thermal neutron flux estimated from the $\mathrm{Au}$ activation method and from the activities of the iron and stainless bolts. The neutron fluxes are in $10^{5} \mathrm{~cm}^{-2} \mathrm{~s}^{-1}$.

\begin{tabular}{|c|c|c|c|c|c|c|c|c|}
\hline \multirow[t]{2}{*}{ Exp. } & \multirow{2}{*}{$\begin{array}{c}\text { Bolt } \\
\#\end{array}$} & \multirow{2}{*}{$\frac{\begin{array}{c}\mathrm{Au} \\
\text { method }\end{array}}{\phi_{\text {th }}}$} & \multicolumn{2}{|c|}{${ }^{56} \mathrm{Mn}$} & \multicolumn{2}{|c|}{${ }^{59} \mathrm{Fe}$} & \multicolumn{2}{|c|}{${ }^{65} \mathrm{Zn}$} \\
\hline & & & $\phi_{\mathrm{th}}$ & Ratio $^{a}$ & $\phi_{\mathrm{th}}$ & Ratio $^{a}$ & $\phi_{\text {th }}$ & Ratio $^{a}$ \\
\hline \multirow[t]{5}{*}{ (C) } & $\# 6$ & 11 & 7.8 & 74 & & - & & - \\
\hline & $\# 6$ ' & $7.3^{b}$ & & - & 14 & 188 & 12 & 161 \\
\hline & $\# 7$ & 4.1 & 3.1 & 75 & & - & & - \\
\hline & $\# 7^{\prime}$ & $7.3^{b}$ & & - & 12 & 169 & 13 & 179 \\
\hline & $\# 8$ & 9.8 & 8.2 & 122 & 15 & 223 & & - \\
\hline (D) & $\# 10$ & 1.2 & 0.9 & 78 & 3 & 258 & & - \\
\hline
\end{tabular}

a: Value when the neutron flux from the Au method equals 100; b: Average of the value of the position \#6 and \#7.

method was applied to estimates the thermal neutron flux, the activity in the bolts reflected the whole energy of the neutrons. The difference between the results from the Au foil method and the bolts method proposed in this paper mainly caused by the fact.

On the other hand, regarding to the activation, iron is better than brass and/or stainless steel. As listed in Table 4, the induced radionuclides, ${ }^{65} \mathrm{Zn}$ in brass and ${ }^{60} \mathrm{Co}$ in stainless steel, have relatively high activities and long half-lives, and the activities of such long half-life nuclides in iron was low. The fact suggests that iron is better than brass and/or stainless steel because of the induced radionuclides from the viewpoint of maintenance and waste management of the cyclotrons.

Special detectors to measure neutrons, i.e.; thermoluminescent dosimeters for neutron detection, and a Bonner sphere spectrometer, were used in some reports [10-15]. Those detectors require particular instruments. Most medical facilities have no such instruments for detecting neutrons. In this study, the bolts in the cyclotron rooms were used as surrogates for neutron detectors. The method requires usual gamma spectrometry and analysis of the elemental compositions. Our results show that the neutron fluxes estimated from the radioactive analysis of the bolts roughly agreed with those evaluated by the Au activation method. Usually, there are a lot of small size bolts or screws in those cyclotron rooms and removing and analyzing them is not so difficult. The analyses will bring effective information of the neutron fluxes in the rooms. Among the bolts, iron and stainless bolts including $\mathrm{Mn}$ are most useful to estimate the neutron fluxes, but the activity analysis should be performed as soon as possible because of the short half-life of ${ }^{56} \mathrm{Mn}$. The method proposed in this study is quite convenient and it will contribute the radiation safety for PET cyclotron facilities.

\section{Conclusion}

A new method to estimate neutron fluxes in PET cyclotron rooms was investigated, i.e.; radioactive analysis of the bolts in the rooms. The neutron fluxes in the PET cyclotron rooms during ${ }^{18} \mathrm{~F}$ production were about $10^{5} \sim 10^{6} \mathrm{~cm}^{-2} \mathrm{~s}^{-1}$. In the brass bolts, ${ }^{69 \mathrm{~m}} \mathrm{Zn},{ }^{65} \mathrm{Zn},{ }^{64} \mathrm{Cu},{ }^{58} \mathrm{Co}$, and ${ }^{60} \mathrm{Co}$ were detected. In the iron bolts, ${ }^{56} \mathrm{Mn},{ }^{54} \mathrm{Mn},{ }^{59} \mathrm{Fe},{ }^{60} \mathrm{Co},{ }^{69 \mathrm{~m}} \mathrm{Zn}$, and ${ }^{65} \mathrm{Zn}$ were detected. In the stainless bolts, ${ }^{58} \mathrm{Co},{ }^{60} \mathrm{Co},{ }^{56} \mathrm{Mn},{ }^{54} \mathrm{Mn}$, and ${ }^{59} \mathrm{Fe}$ were detected. Neutron fluxes estimated from the activities of ${ }^{56} \mathrm{Mn}$ agreed well with those evaluated from the Au foil activation method. Analysis of radioactivity and elemental compositions of the bolts in the rooms were helpful for estimating the neutron fluxes in the rooms. The feasibility of estimating the neutron fluxes in cyclotron rooms by means of radioactive analysis of bolts in the rooms was proven.

Acknowledgment. The gamma spectroscopy system in Radioisotope Research Center Nagoya University was used for this study.

\section{References}

1. Rohren, E. M., Turkington, T. G., Coleman, R. E.: Clinical applications of PET in oncology. Radiology 231, 305 (2004).

2. Qaim, S. M.: Use of cyclotrons in medicine. Radiat. Phys. Chem. 71, 917 (2004).

3. Shields, A. F.: Positron emission tomography measurement of tumor metabolism and growth: Its expanding role in oncology. Mol. Imag. Biol. 8, 141 (2006)

4. PET\&PET, available at http://www.jcpet.jp/1-3-4-1, accessed 25 November 2009 [in Japanese].

5. O’Donnell, R. G., Vintro, L. L., Duffy, G. L., Mitchell, P. I.: Measurement of the residual radioactivity in the front foil of a target assembly in a modern medical cyclotron. Appl. Radiat. Isot. 60 539 (2004)

6. Ito, S., Saze, T., Sakane, H., Ito, S., Ito, S., Nishizawa, K.: Tritium in $\left[{ }^{18} \mathrm{O}\right]$ water containing $\left[{ }^{18} \mathrm{~F}\right]$ fluoride for $\left[{ }^{18} \mathrm{~F}\right] \mathrm{FDG}$ synthesis. Appl. Radiat. Isot. 61, 1179 (2004).

7. Ito, S., Sakane, H., Deji, S., Saze, T., Nishizawa, K.: Radioactive byproducts in $\left[{ }^{18} \mathrm{O}\right] \mathrm{H}_{2} \mathrm{O}$ used to produce ${ }^{18} \mathrm{~F}$ for $\left[{ }^{18} \mathrm{~F}\right] \mathrm{FDG}$ synthesis. Appl. Radiat. Isot. 64, 298 (2006).

8. Marengo, M., Lodi, F., Magi, S., Cicoria, G., Pancaldi, D., Boschi, S.: Assessment of radionuclidic impurities in $2-\left[{ }^{18} \mathrm{~F}\right]$ fluoro2-deoxy-D-glucose $\left(\left[{ }^{18} \mathrm{~F}\right] \mathrm{FDG}\right)$ routine production. Appl. Radiat. Isot. 66, 295 (2008).

9. Mochizuki, S., Ogata, Y., Hatano, K., Abe, J., Ito, K., Ito, Y., Nishino, M., Miyahara, H., Ishigure, N.: Measurement of the induced radionuclides in production of radiopharmaceuticals for positron emission tomography (PET). J. Nucl. Sci. Tech. 43, 348 (2006).

10. Vega-Carrillo, H. R.: Neutron energy spectra inside a PET cyclotron vault room. Nucl. Instrum. Methods Phys. Res. A 463 , 375 (2001).

11. Hertel, N. E., Shannon, M. P., Wang, Z. L., Valenzano, M. P., Mengesha, W., Crowe, R. J.: Neutron measurements in the vicinity of a self-shielded PET cyclotron. Radiat. Prot. Dosim. 108, 255 (2004) 
12. Méndez, R., Iniguez, M. P., Martí-Climent, J. M., Penuelas. I., Vega-Carrillo, H. R., Barquero, R.: Study of the neutron field in the vicinity of an unshielded PET cyclotron. Phys. Med. Biol. 50, 5141 (2005)

13. Pevey, R., Miller, L. F., Marshall, B. J., Townsend, L. W., Alvord, B.: Shielding for a cyclotron used for medical isotope production in China. Radiat. Prot. Dosim. 115, 415 (2005).

14. Fernández, F., Amgarou, K., Domingo, C., Garcia, M. J., Quincoces, G., Marti-Climent, J. M., Medez, R., Barquero, R.: Neutron spectrometry in a PET cyclotron with a Bonner sphere system. Radiat. Prot. Dosim. 126, 371 (2007).

15. Ogata, Y., Ishigure, N., Mochizuki, S., Ito, K., Hatano, K., Abe, J., Miyahara, H.: Neutron flux inside and outside a PET cyclotron room. Japan. J. Radiat. Safety Manage. 7, 35 (2008) [in Japanese].

16. Misawa, T., Unesaki, H., Ichihara, C., Pyeon, H. C., Shiroya, S. Joint Reactor Laboratory Course for students in KUCA, KURRITR-433, Kyoto (2004) [in Japanese]. 